\author{
E. O. McFalls \\ D. J. Duncker \\ H. Ward \\ P. Fashingbauer
}

\title{
Impaired endothelium-dependent vasodilation of coronary resistance vessels in severely stunned porcine myocardium
}

Received: 4 April 1995

Returned for revision: 28 April 1995

Revision received: 28 May 1995

Accepted: 17 September 1995

Supported by grants from the Minnesota Medical Foundation, American Heart Association-Minnesota Affiliate and VA Merit Review (E.O.M.)
Dr. E. O. McFalls $(\bowtie) \cdot$ H. Ward

P. Fashingbauer

Division of Cardiology

University of Minnesota-VA Medical Center

1 Veterans Drive

Minneapolis, Minnespota 55417, USA

D. J. Duncker

Laboratory for Experimental Cardiology

Thoraxcenter

Erasmus University

Rotterdam, The Netherlands

\begin{abstract}
The effect of stunning on endothelium-dependent responses of resistance vessels in vivo remains of interest. We utilized the coronary pressure-flow relationship during maximal vasodilation in anesthetized swine to identify subtle changes in flow reserve within stunned myocardium. Prior to and following stunning, the coronary pressure-flow relationship during maximal doses of intracoronary adenosine was compared with that of the endotheliumdependent vasodilator ATP. In 11 anesthetized swine, $30 \mathrm{~min}$ of partial LAD occlusion and 40 min of reperfusion reduced fractional shortening from $16 \pm 4 \%$ to $6 \pm 5 \%(\mathrm{p}<0.05)$. This caused a rigtward shift of the coronary pressure-flow relationships during infusions of either adenosine or ATP, suggestive of increased extra vascular compressive forces. With adenosine, the slope of the linear portion of the relationship (i.e., coronary pressures $>30 \mathrm{mmHg}$ ) was $1.31 \pm 0.54 \mathrm{ml} / \mathrm{min}-\mathrm{mmHg}$ at baseline and $1.30 \pm 0.55 \mathrm{ml} / \mathrm{min}-\mathrm{mmHg}$ following stunning (NS). With ATP
\end{abstract}

however, the slope decreased from $1.34 \pm 0.48 \mathrm{ml} / \mathrm{min}-\mathrm{mmHg}$ at baseline to $1.08 \pm 0.47 \mathrm{ml} / \mathrm{min}$ $\mathrm{mmHg}$ following reperfusion $(\mathrm{p}<$ 0.05 ), indicating an attenuation of endothelium-dependent vasodilator capacity. In five of the animals, the slope of the pressure-flow relationship during intracoronary nitroprusside was unchanged post-stunning, which is similar to the adenosine results. In conclusion, the data support the hypothesis that endothelium-dependent vasodilation of resistance vessels in the intact animal is altered within severely stunned myocardium. The rightward shift of the coronary pressure-flow relationships with both classes of vasodilators suggest that extra vascular factors may also play a role in limiting coronary flow reserve.

Key words Adenosine - ATP nitroprusside - vasodilator capacity extra vascular compressive forces coronary pressure-flow relationship - swine

\section{Introduction}

Following myocardial ischemia and reperfusion, the capacity of the coronary vasculature to maximally vasodilate may be reduced. This is particularly true following a prolonged ischemic period which is sufficient enough to produce necrosis. Proposed mechanisms for such an abnormal flow response include mechanical obstruction from capillary damage (1), neutrophil plugging (2) and tissue edema (3) or increased resistance due to enhanced 
vasomotor tone (4) or ischemic contracture (5). Additionally, prolonged ischemia and reperfusion alters the endothelium, resulting in a reduction in the release and/or response of endothelium-dependent relaxing factor (EDRF) in both conductance $(6,7)$ and resistance (8) vessels.

In models where myocardial function is reversibly depressed following a brief ischemic period ("stunning"), it is not clear whether endothelial cell function as measured by endothelium-dependent vasodilation is reduced. Fifteen minutes of partial coronary occlusion in pigs (9) and four 5-min opisodes of intermittent coronary occlusion in dogs (10) followed by reperfusion are sufficient to attenuate endothelium-dependent relaxation of coronary artery rings in vitro. In vivo, such brief periods have not been shown to alter the response of endothelium-dependent vasodilators, despite the presence of myocardial stunning $(11,12)$. These studies were done with ischemia $\leq 10 \mathrm{~min}$ in duration however, which may not be sufficient to alter the endothelium. One explanation for the discordance of in vitro and in vivo results is that the time of ischemia may be too brief to induce a measurable response in the intact animal. Ehring et al. have recently shown that cholinergic flow responses within stunned myocardium of dogs is abnormal only when the time of ischemia exceeds $15 \mathrm{~min}$ (13). Free radicals are likely to be responsible for the disruption of endothelial cells and their concentrations are proportional to the length of both ischemia (14) and reperfusion (15). Therefore, it is important that studies of endothelium-dependent vasomotion following stunning utilize models which maximize the ischemic burden, yet avoid periods sufficient to induce necrosis.

The aim of this study was to test whether coronary resistance vessel dilation with the endothelium-dependent vasodilator ATP differs from that of the endotheliumindependent vasodilator adenosine, following prolonged ischemia ( 30 minutes) and reperfusion. We used the coronary pressure-flow relationship during maximal vasodilation to allow discrimination between vascular and extravascular components which might affect maximal coronary blood flow.

\section{Materials and methods}

All experiments were performed in accordance with the guiding principles in the care and use of laboratory animals as approved by the Council of the American Physiological Society and under the regulations of the Animal Care Committee of the VA Medical Center, University of Minnesota.

\section{General preparation}

After an overnight fast, domestic swine of either sex (34$42 \mathrm{~kg}$ ) were used for these experiments. Sedation was provided with an intramuscular bolus of ketamine $(20 \mathrm{mg} / \mathrm{kg})$ followed by a bolus infusion of pentobarbitone $(10 \mathrm{mg} / \mathrm{kg})$ into an ear vein. Animals were intubated, connected to a Harvard pump respirator and ventilated with a mixture of oxygen and room air. The respirator was adjusted throughout the experiment to ensure physiologic arterial $\mathrm{pH}$ (7.35 - 7.45), $\mathrm{PCO}_{2}(35-45 \mathrm{~mm} \mathrm{Hg})$ and $\mathrm{PO}_{2}(>100 \mathrm{~mm} \mathrm{Hg})$. The left external jugular vein was exposed via cut down and cannulated with two $7 \mathrm{~F}$ catheters. Both the left carotid and right femoral arteries were isolated and cannulated with $7 \mathrm{~F}$ catheters. Anesthesia was initiated with a bolus of intravenous (iv) alpha chloralose $(150 \mathrm{mg} / \mathrm{kg})$ and supplemented throughout the experiment with low dose sodium pentobarbitone $(5 \mathrm{mg} / \mathrm{kg} / \mathrm{h})$. Succinyl choline $(0.25 \mathrm{mg}$ iv) was infused for muscle relaxation and a midline sternotomy was performed. The heart was suspended in a pericardial cradle, the left mammary vessels were ligated and the left second rib was removed for ease of further instrumentation. The proximal portion of the left anterior descending coronary artery (LAD) was dissected free from its adventitia onto which a Doppler flow probe (20 MHz, $3.0 \mathrm{~mm}$; Hartley Laboratory, Houston, TX) was placed just proximal to a hydraulic occluder. The position and stability of the flow probe around the vessel were ensured and coronary blood flow measures were determined as previously described (16). Just distal to the occluder, a small silastic catheter $(0.3 \mathrm{~mm}$ ID, $0.6 \mathrm{~mm}$ OD) was inserted (17) and used for measurement of intracoronary pressure and infusion of the vasodilators. A $5 \mathrm{~F}$ Millar catheter was then inserted and secured into the apex for the measurement of left ventricular pressure (LV) and its first derivative ( $\mathrm{LV} \mathrm{dP/dt}$ ). Regional segment length changes were determined in the area perfused by the LAD using a pair of ultrasonic crystals placed into the subendocardial layers, approximately $8-10 \mathrm{~mm}$ apart. Systolic shortening was calculated by subtracting endsystolic length (time of peak negative $\mathrm{dP} / \mathrm{dt}$ ) from enddiastolic length (time of onset of positive $\mathrm{dP} / \mathrm{dt}$ ) and expressed as a percent of end-diastolic length.

\section{Experimental protocol}

Following a 30-min stabilization period, baseline measurements of systemic and coronary hemodynamics were obtained. The pressure maximal coronary flow relationship was then determined for either adenosine $(40 \mu \mathrm{g} / \mathrm{kg}$ ) min) or ATP $(40 \mu \mathrm{g} / \mathrm{kg} / \mathrm{min})$ at doses which increased coronary blood flow maximally. The maximal dose 
response was ensured at the beginning of each experiment by observing the flow response over a 5 -min steadystate infusion. The order of drugs tested was selected randomly for each experiment and followed both pre- and post-stunning. Each agent was infused for $3-5$ min until a steady state was reached. By adjusting the hydraulic occluder, at least six coronary pressureflow points were obtained over a wide range. Recordings were obtained at each interval for coronary blood flow and pressure while turning the stop cock to allow pressure measurements. This interruption of infusion was brief and did not affect the maximal flow response. The final point was an occlusion of $5 \mathrm{~s}$ duration which allowed an estimate of pressure-zero flow. The entire cycle lasted no more than $60 \mathrm{~s}$ and was repeated after 5 min. Following each infusion, coronary blood flow was allowed to return to baseline prior to testing the next agent.

Partial coronary occlusion was then induced by adjusting the hydraulic occluder so that coronary blood flow was reduced by at least $80 \%$. We have previously shown that this degree of ischemia is sufficient to cause myocardial stunning yet minimize ventricular fibrillation $(11,18)$. The occluder was released after $30 \mathrm{~min}$ of ischemia, followed by $40 \mathrm{~min}$ of complete reperfusion. Recordings of systemic and coronary hemodynamics were then obtained and coronary pressure-flow points were acquired during constant infusion of each agent as described above.

In five of the animals, the pressure-flow relationship pre and post-stunning was also characterized with the endothelium-independent vasodilator nitroprusside. Coronary flow-pressure points were obtained during a constant intracoronary infusion of the agent at a dose of $3-5 \mu \mathrm{g} / \mathrm{kg} / \mathrm{min}$. This dose was chosen to minimize the effects on systemic blood pressure and heart rate due to recirculation. Similar to ATP and adenosine, the coronary pressure-flow relationships post-stunning were compared to baseline values.

At $3 \mathrm{~h}$ of reperfusion, hearts were extracted, sliced into $5-10 \mathrm{~mm}$ sections and immediately placed into a warm buffered solution of nitro blue tetrazolium. The absence of necrosis was confirmed 20 min later in all animals.

\section{Data analysis and statistics}

For each vasodilator, coronary pressure-flow relationships during vasodilation were determined both pre- and post-stunning. These were derived by 2 nd order polynomial fits for all pressure-flow points and by 1st order fits for all pressure-flow points with coronary pressures $>30 \mathrm{~mm} \mathrm{Hg}$. This was arbitrarily chosen so that a range on the linear portion of the curve could be separately analyzed. We have previously shown that the slope and intercepts of the coronary pressure-flow relationship during maximal adenosine are reproducible with at least four measurements obtained over a $2-3$ hour experimental protocol (19).

The results are expressed as means \pm SD or SEM if specified. Statistical differences are tested at the $p<0.05$ level by ANOVA repeated measures (Fisher's protected least significant difference plus F-test).

\section{Results}

Fifteen animals were used for these experiments. Four animals experienced ventricular fibrillation during the ischemic period and are not included in the results. Ventricular fibrillation occurred in three animals in the first 5 min of reperfusion and were cardioverted to normal sinus rhythm within $10 \mathrm{~s}$. These animals are included in the results.

\section{Systemic hemodynamics}

At baseline, mean arterial blood pressure was $86 \pm 15 \mathrm{~mm}$ $\mathrm{Hg}$ and heart rate was $98 \pm 17$ beats per minute and both remained constant throughout the experimental protocol (Table 1). Ischemia increased left ventricular end-diastolic pressure and decreased $\mathrm{LV} \mathrm{dP} / \mathrm{dt}_{\max }$ and these changes were sustained following reperfusion, although LVEDP recovered slightly. Coronary blood flow was $31 \pm$ $14 \mathrm{ml} / \mathrm{min}$ at baseline and was reduced by at least $80 \%$ to $4 \pm 2 \mathrm{ml} / \mathrm{min}$ during ischemia $(\mathrm{p}<0.05)$. At $40 \mathrm{~min}$ of reperfusion, coronary blood flow returned to $30 \pm 11 \mathrm{ml} /$ $\min$.

At baseline, systolic segment shortening in the myocardium perfused by the LAD was $16 \pm 4 \%$. Ischemia increased both end-diastolic and end-systolic lengths and decreased shortening to $1 \pm 3 \%$. Following reperfusion, severe stunning had occurred as manifested by increased lengths and severely reduced systolic shortening of $6 \pm$ $5 \%(\mathrm{p}<0.05$ vs. baseline $)$.

\section{Coronary pressure-flow relationship}

The coronary pressure-flow relationship was generated prior to and following stunning by obtaining multiple pressure-flow points during an intracoronary infusion of each of the vasodilators. Points were obtained over a wide distribution of perfusion pressures, allowing the relationship to be defined in ischemic and non-ischemic ranges. Figure 1 shows a representative tracing from one animal following 
Impaired endothelium-dependent vasodilation of coronary resistance vessels

Table 1 Systemic hemodynamics and regional myocardial function at baseline, during ischemia and post-reperfusion.

\begin{tabular}{|c|c|c|c|c|c|c|c|c|c|c|}
\hline & \multicolumn{4}{|c|}{ Systemic Hemodynamics } & \multicolumn{3}{|c|}{ Coronary blood flow } & \multicolumn{3}{|c|}{ Regional Function } \\
\hline & $\begin{array}{l}\mathrm{MAP} \\
(\mathrm{mmHg})\end{array}$ & $\begin{array}{l}\text { HR } \\
\text { (beats/min) }\end{array}$ & $\begin{array}{l}\text { LVEDP } \\
(\mathrm{mmHg})\end{array}$ & $\begin{array}{l}\mathrm{LVdP} / \mathrm{dt}_{\max } \\
(\mathrm{mmHg} / \mathrm{sec})\end{array}$ & $\begin{array}{l}\text { Rest } \\
(\mathrm{ml} / \mathrm{min})\end{array}$ & $\begin{array}{l}\text { Adenosine } \\
(\mathrm{ml} / \mathrm{min})\end{array}$ & $\begin{array}{l}\text { ATP } \\
(\mathrm{ml} / \mathrm{min})\end{array}$ & $\begin{array}{l}\text { ESL } \\
(\mathrm{mm})\end{array}$ & $\begin{array}{l}\mathrm{EDL} \\
(\mathrm{mm})\end{array}$ & $\begin{array}{l}\text { FS } \\
(\%)\end{array}$ \\
\hline Baseline & $86 \pm 15$ & $98 \pm 17$ & $10 \pm 2$ & $1836 \pm 577$ & $31 \pm 14$ & $148 \pm 96$ & $146 \pm 91$ & $7.7 \pm 1.7$ & $8.9 \pm 2.2$ & $16 \pm 4$ \\
\hline $\begin{array}{l}\text { Ischemia } \\
\text { (@15 min) }\end{array}$ & $81 \pm 17$ & $97 \pm 18$ & $15 \pm 5^{*}$ & $1414 \pm 464^{*}$ & $4 \pm 2^{*}$ & $\mathrm{~N} / \mathrm{A}$ & $\mathrm{N} / \mathrm{A}$ & $9.8 \pm 1.9^{*}$ & $9.9 \pm 2.2^{*}$ & $1 \pm 3^{*}$ \\
\hline $\begin{array}{l}\text { Reperfusion } \\
(@ 40 \mathrm{~min})\end{array}$ & $86 \pm 21$ & $102 \pm 18$ & $13 \pm 4^{*}$ & $1445 \pm 465^{*}$ & $30 \pm 11$ & $141 \pm 84$ & $112 \pm 56$ & $9.4 \pm 1.9^{*}$ & $9.8 \pm 2.4^{*}$ & $6 \pm 5^{*}$ \\
\hline
\end{tabular}

MAP (mean arterial pressure); HR (heart rate); LVEDP (left ventricular end-diastolic pressure); ESL (end-systolic length); EDL (enddiastolic length); FS (\% systolic shortening). means $\pm \mathrm{sd}(\mathrm{n}=11) ;{ }^{*} \mathrm{p}<0.05$ vs. baseline; ANOVA

stunning. Phasic coronary blood flow and pressure are shown prior to and following infusion of intracoronary ATP and mean flows and pressures are shown during several levels of reduced perfusion pressure. Coronary flows

Fig. 1 This is a representative example of a strip chart recording in one animal following stunning, showing EKG, aortic (AO), left ventricular $(\mathrm{LV})$ and coronary perfusion $(\mathrm{CP})$ pressures $(\mathrm{P})$, coronary blood flow (CBF), segment length shortening (SL) in the LAD region, and LV dP/dt. Tracings are taken pre- and post-infusion of intracoronary ATP and several mean coronary blood flows and perfusion pressures are shown while gradually tightening the hydraulic occluder during the infusion. The coronary pressure-flow relationship during vasodilation could then be generated from several of these points. during vasodilation was were determined at several perfusion pressures from the equations of the original 2 nd order curve fits obtained during infusion of the agent. The $\mathrm{r} 2$ of the relationships of each of the fits were very close to 1 and therefore the calculated flow points were an accurate estimate of measured points. Figure 2(A) shows the pressure-flow relationships during infusion of adenosine for all animals both pre and post-stunning. Using the mean values from each of the animals, the figure demonstrates that stunning caused a translation of coronary flow response along the pressure axis, with significant differences in flow noted below $50 \mathrm{mmHg}$. The relationship also shows an increase in coronary perfusion pressure at the extrapolated zero flow point. Above $50 \mathrm{mmHg}$, the points

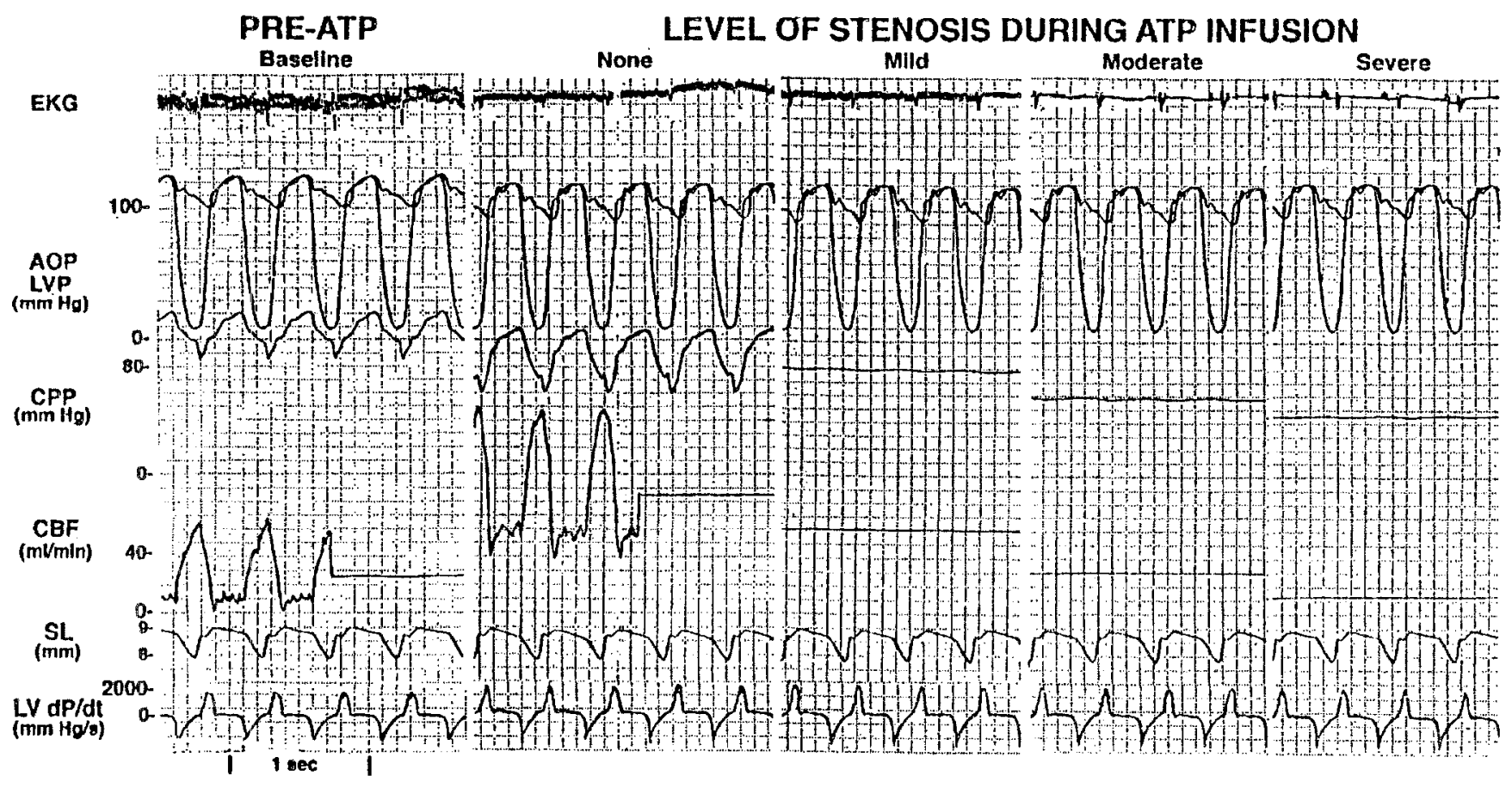


Fig. 2 Coronary flow-pressure relationships are shown at baseline and following stunning during maximal vasodilation with (A) adenosine and (B) ATP (means \pm SEM; $\mathrm{n}=11$ ). Coronary flows during each of the listed perfusion pressures were determined from the equations of the original 2 nd order fits obtained during infusion of each of the agents. A rightward shift is noted with both vasodilators following stunning, suggesting that extravascular factors were increased. Unlike with adenosine, the slope of the linear portion of the curve with ATP following stunning was reduced, indicating that vascular factors (i.e., endotheliumdependent responses) were attenuated. (*p $<0.05$ vs baseline measure).
A

$0=$ Adenosine Baseline - = Adenosine Reperfusion

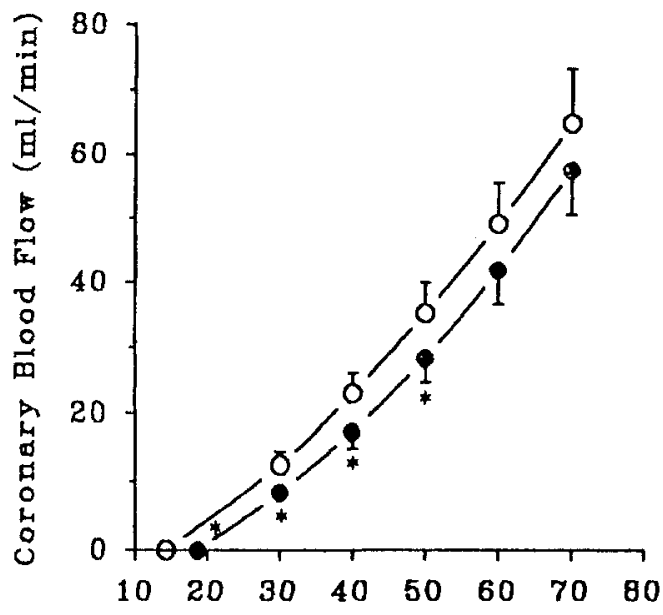

Coronary Pressure ( $\mathrm{mmHg}$ )
B

$\square=\operatorname{ATP}$ Baseline

- ATP Reperfusion

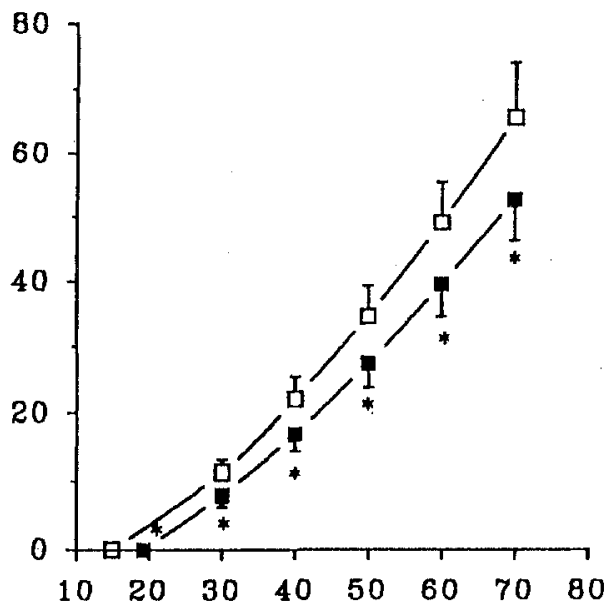

Coronary Pressure ( $\mathrm{mmHg}$ ) are not significantly different pre and post-stunning and the linear portions of each curve are parallel.

The coronary pressure-flow relationships during infusion of the endothelium-dependent vasodilator ATP are depicted in Fig. 2(B). As with Fig. 2(A), coronary flows during each of the listed perfusion pressures were determined from the equations of the original 2 nd order fits obtained during infusion of ATP. Similar to adenosine, a rightward shift on the pressure axis was observed during ATP infusion following stunning. However, stunning decreased the maximal flow responses to ATP at higher perfusion pressures as well which caused a divergence of the baseline and post-stunning curves.

Slope of the coronary pressure-flow relationship

Pressure-flow points were chosen above a coronary perfusion pressure of $30 \mathrm{mmHg}$ in view of the linear portion of

Table 2 Coronary pressure-flow relationships at baseline and postreperfusion during either adenosine or ATP

\begin{tabular}{lllll}
\hline & \multicolumn{2}{c}{ Adenosine } & \multicolumn{2}{c}{ ATP } \\
& $\mathrm{P}_{\mathrm{ZF}}$ & Slope & $\mathrm{P}_{\mathrm{ZF}}$ & Slope \\
\hline Basline & $15 \pm 3$ & $1.31 \pm 0.54$ & $15 \pm 3$ & $1.34 \pm 0.48$ \\
$40 \mathrm{~min}$ Post-reperfusion & $19 \pm 4^{*}$ & $1.30 \pm 0.55$ & $20 \pm 5^{*}$ & $1.08 \pm 0.47^{*}$
\end{tabular}

$\mathrm{P}_{\mathrm{ZF}}$ (measured pressure at zero flow, $\mathrm{mmHg}$ ); slope of 1 st order fit from coronary pressure points $>30 \mathrm{mmHg}(\mathrm{ml}-\mathrm{mmHg} / \mathrm{min})$; means $\pm \mathrm{sd} ; \mathbf{n}=11 ; * \mathrm{p}<0.05$ vs baseline; ANOVA the relationships. The slopes of the 1st order fits are shown in Table 2 for both ATP and adenosine at baseline and following stunning. With adenosine, stunning did not alter the slope of the line suggesting that the capacity of the vasculature to vasodilate remained intact. In contrast, the slope of the relationship during ATP was lower following stunning in all animals, indicating altered endotheliumdependent response. Table 2 shows that the measured coronary pressure at which blood flow was zero (Pzf) increased following stunning during infusions of either adenosine or ATP.

The pressure-flow relationship during nitroprusside

In five of the animals, the coronary pressure-flow relationship during vasodilation was tested with the endothelium-independent agent nitroprusside $(3-5 \mu \mathrm{g} / \mathrm{kg} /$ min). Some recirculation of the drug was noted as mean arterial pressure dropped $10-15 \mathrm{mmHg}$ during the infusion. Figure 3 shows the pressure-flow relationships during infusion of nitroprusside for all five animals both pre and post-stunning. As with Fig. 2, the flows at each of the listed perfusion pressures were determined from the equations of the original 2 nd order curve fits obtained during infusion of the vasodilator. At baseline, the slope of the linear portion of the relationship was $0.55 \pm 0.28 \mathrm{ml}-$ $\mathrm{mmHg} / \mathrm{min}$ and post-stunning was $0.62 \pm 0.25 \mathrm{ml}-\mathrm{mmHg} /$ $\min (\mathrm{NS})$. The pressure at zero flow (Pzf) was $14.0 \pm$ $2.2 \mathrm{mmHg}$ prior to stunning and increased slightly to 15.3 $\pm 1.7 \mathrm{mmHg}$ post-stunning $(\mathrm{p}=0.06)$. These data give 


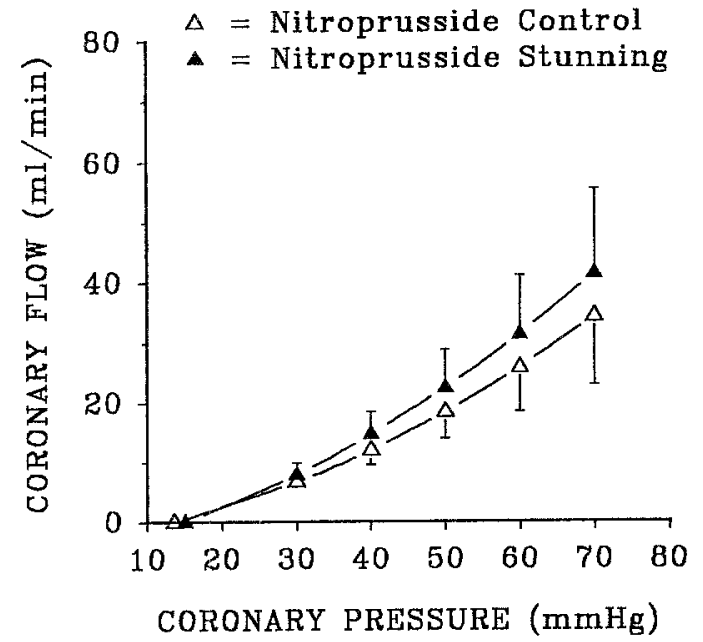

Fig. 3 The coronary flow-pressure relationships during intracoronary nitroprusside are shown in five of the animals at baseline and following stunning. Coronary flows during each of the listed perfusion pressures were determined from the equations of the original 2nd order fits obtained during infusion of the vasodilator. The curves demonstrate that no reduction in the slope of the pressure-flow relationship was observed during endothelium-independent vasodilation following stunning.

further support that endothelium-independent vasodilation is less altered than endothelium-dependent vasodilation in this model of stunning.

\section{Discussion}

There is enormous interest in determining whether models of ischemia and reperfusion impair the capacity of the coronary vasculature to maximally vasodilate. In particular, such information may give important insight into how the reperfused myocardium can adjust to subsequent myocardial oxygen demands. In this study, we have characterized changes in vasodilator capacity within severely stunned but viable porcine myocardium using the coronary pressure-flow relationship. The principal findings are that in severely stunned myocardium: 1) endotheliumdependent vasodilation is attenuated as determined from the linear portion of the coronary pressure-flow relationship during infusion of ATP, and 2) extravascular compressive forces impede maximal coronary blood flow as manifested by a rightward shift of the coronary pressure-flow relationship.
Vasodilator capacity in the presence of necrosis

In models of prolonged ischemia where heterogeneous necrosis is likely to occur, the capacity of the vascular bed to maximally vasodilate is impaired. A number of mechanisms have been proposed to explain these observations including mechanical obstruction from capillary damage (1), neutrophil plugging (2) and tissue edema (3) or increased resistance due to enhanced vasomotor tone (4) or ischemic contracture (5). Johnson et al. (20) attempted to dissociate maximal vasodilator capacity from the presence of necrosis in a swine model of ischemia and reperfusion. Using the coronary pressure-flow relationship during constant adenosine infusion, they showed that the vasodilator response is unchanged after $20 \mathrm{~min}$ of ischemia and reperfusion. It was depressed after $40 \mathrm{~min}$ of ischemia and reperfusion however at a time when necrosis had also developed. They did not examine a more critical time point of ischemic time such as $30 \mathrm{~min}$, which might have shown vascular abnormalities in the absence of permanent damage.

Vasodilator capacity in viable post-ischemic myocardium

In models of ischemia-reperfusion in which necrosis does not develop, it is controversial whether maximal vasodilation is impaired. In dogs, $15 \mathrm{~min}$ of coronary occlusion followed by reperfusion reduced the maximal increment in coronary blood flow with either intravenous (21) or intracoronary (22) adenosine. Other studies are at variance with these results however. Despite a reduction in peak reactive hyperemia, maximal vasodilation with adenosine was preserved in anesthetized $(23,24)$ and conscious (25) dog models of stunning. One potential reason for this discrepancy is the technique used to measure vasodilator capacity. Because of the steepness of the pressureflow relationship during maximal vasodilation, small changes in pressure induce large changes in coronary blood flow with the potential for obscuring subtle changes in vasodilator capacity. For these reasons, the coronary pressure-flow relationship during maximal vasodilation is a more sensitive means of determining changes in vascular reactivity following reperfusion (26). The slope of the linear portion of the pressure-flow relationship reflects the maximum coronary conductance while the pressure at zero flow (Pzf) represents the effective coronary back pressure. We have previously shown that $15 \mathrm{~min}$ of ischemia and reperfusion in swine does not reduce but actually increases the slope of the linear portion of the coronary pressure-flow relationship during adenosine with pressure-flow points $\geq 40 \mathrm{mmHg}$ (18). This enhanced flow response did not appear to be related to the decreased 
compressive forces of stunning because recruitment of systolic function with dobutamine did not alter the slopes. The same mechanism was observed in a few of the animals in this study, explaining why adenosine pressure-flow points post-stunning are significantly different from baseline at 40 and $50 \mathrm{mmHg}$ but not at higher pressure points. Both of these studies give further support that vascular reactivity to adenosine is not depressed within stunned, viable myocardium.

Endothelium-dependent vasodilation following stunning

It has previously been shown that the endothelial cell undergoes morphological and functional changes following ischemia and reperfusion $(6,7)$. In models of myocardial stunning in the absence of necrosis, in vitro measures of endothelium-dependent vasodilation are depressed $(9$, $10)$. In vivo however, it is controversial whether myocardial stunning is associated with changes in endotheliumdependent vasodilation $(11,12)$. Pelc et al. (27) showed that $45 \mathrm{~min}$ of coronary occlusion followed by $60 \mathrm{~min}$ of reperfusion in dogs attenuated subendocardial perfusion during intracoronary infusions of either bradykinin or acetylcholine but not nitroprusside. Although these results are consistent with the present study, it is not clear whether necrosis also occurred in that model. We have previously shown that following 10 min of partial coronary occlusion and $30 \mathrm{~min}$ of reperfusion in swine, minimal coronary vascular resistances were not different between adenosine and ATP, despite significant stunning (11). The present study suggests that longer periods of ischemia are an important factor related to subsequent reductions in endothelium-dependent vasodilation. Ehring et al. have recently shown that cholinergic flow responses within stunned myocardium of dogs is abnormal only when the time of ischemia exceeds $15 \mathrm{~min}$ (13). In support of these results, free radicals have been implicated as the cause of the endothelial cell disruption (28) which in turn, quantitatively correlate with the amount of ischemic time (14).

\section{Effects of extravascular factors on vasodilator capacity}

In addition to changes in vascular reactivity, the coronary pressure-flow relationship gives important information about extravascular factors which might alter maximal coronary blood flow at any coronary perfusion pressure. Alterations in heart rate (29), left ventricular end-diastolic pressure $(30)$ and contractility $(31,32)$ all can affect maximal coronary blood flow and need to be considered in the interpretation of flow reserve studies following ischemia-reperfusion. Following stunning, we observed a rightward shift of the curvilinear portion of the coronary pressure-flow relationship with all vasodilators as well as an increased pressure zero-flow. It is likely that the increased left ventricular end-diastolic pressure following stunning was sufficient to induce these vascular changes. Aversano et al. (30) showed in a capacitance free model of open-chest dogs that an increment of $5 \mathrm{mmHg}$ in preload is sufficient to cause a right-ward shift of the coronary pressure-flow relationship. It is unlikely that other hemodynamic changes in these experiments could have been responsible for these changes. Heart rate and arterial pressure remained unchanged and contractility as measured by $\mathrm{LV} \mathrm{dP} / \mathrm{dt}_{\max }$ was decreased. The latter would have been expected to increase rather decrease maximal coronary blood flow (32).

The effects of extravascular factors on the coronary pressure-flow relationship following stunning is undoubtedly complex and it is possible that additional effects played a role in the rightward shift of the relationships. Dauber et al. (33) have shown that brief periods of ischemia and reperfusion induce microvascular injury in dogs, as measured by the rate of extravascular accumulation of radiolabeled protein. This could lead to edema formation and increased extravascular compressive forces. The degree of injury is attenuated in the presence of free radical scavengers (28), which might also explain why the rightward shift is more notable following prolonged ischemic times, which increase free radicals post-reperfusion (14).

During the nitroprusside infusion, the rightward shift of the pressure-flow relationship following stunning was not as obvious as with adenosine. A number of factors need to be considered in this regard. Firstly, we cannot exclude that some of the rightward shift during adenosine was a result of endothelium-dependent mechanisms. These would be expected to be less than with ATP but could be enhanced during low perfusion pressures. Secondly, because of recirculation of the intracoronary nitroprusside, the effects on systemic hemodynamics during nitroprusside were much greater than that of adenosine. Both arterial and end-diastolic pressures were lower during the infusion of nitroprusside which likely reduced the effects of extravascular compression on maximal flow.

\section{Methodological considerations}

These experiments were not performed during constant perfusion pressure and thus have the limitations of the capacitance effect on proximal coronary vessels. To minimize these effects, we have measured coronary pressures and blood flows which have been averaged over the 
cardiac cycle. We have also included measures of pressure zero flow which have been obtained after $5 \mathrm{~s}$ of coronary occlusion. Although it is controversial whether such measures can be obtained accurately (26), the absence of collaterals in the pig model make it more reliable than measures obtained from dogs. Our values are consistent with prior studies in swine under resting conditions (34).

The mechanism of vasodilation for any agent is often complex in the intact animal. In vitro however, adenosine has been shown to induce vasodilation independent of the endothelium (35), which is distinctly different from ATP, which involves endothelium-dependent mechanisms (36). Our data in this model of stunning support those findings that specific sites of actions can be descriminated in vivo.

A potential limitation of this study is that endotheliumdependent vasodilators other than ATP were not tested. The advantage of ATP is that it acts directly on endothelial receptors, stimulating the release of nitric oxide. It also induces near maximal vasodilation without causing significant recirculation and systemic hypotension.

\section{Conclusions}

We have shown that severe myocardial stunning in swine is associated with altered endothelium-dependent responses of resistance vessels in the in tact animal. The changes are characterized by a reduction of the slope of the linear portion of the coronary pressure-flow relationship during infusion of maximal doses of ATP. In addition, extravascular factors such as increased left ventricular end-diastolic pressure or edema may also be responsible for limiting flow reserve as shown by a rightward shift of the relationship with both adenosine and ATP.

\section{References}

1. Armiger L, Gavin $I$ (1975) Changes in the microvasculature of ischemic and infarcted myocardium. Lab Invest 33: $51-56$

2. Ambrosio $G$, Weisman $H$, Mannisi J, Becker L (1989) Progressive Impairment of Regional Myocardial Perfusion After Initial Restoration of Postischemic Blood Flow. Circulation 80: 1846-1861

3. Kloner R, Ganote C, Jennings R (1974) The "no-reflow" phenomenon after temporary coronary occlusion in the dog. J Clin Invest 54: 1496-1508

4. Willerson J, Watson J, Hutton I, Templeton G, Fixler D (1975) Reduced myocardial reflow and increased coronary vascular resistance following prolonged myocardial ischemia in the dog. Circ Res 36: 771-781

5. Powers E, DiBona D, Powell W (1984) Myocardial cell volume and coronary resistance during diminished coronary perfusion. Am J Physiol 247: H467$\mathrm{H} 477$

6. Mehta J, Nichols W, Donnelly W, Lawson D, Saldeen T (1989) Impaired canine coronary vasodilator response to acetylcholine and bradykinin after occlusion reperfusion. Circ Res 64: 43-54
7. VanBenthuysen K, McMurtry I (1987) Reperfusion after acute coronary occlusion in dogs impaits endotheliumdependent relaxation to acethylcholine and augments contractile reactivity in vitro. J Clin Invest 79: 265-274

8. Quillen J, Sellke F, Brooks L, Harrison D (1990) Ischemia-reperfusion impairs endothelium-dependent relaxation of coronary microvessels but does not affect large arteries. Circulation 82: 586-594

9. Gross G, O'Rourke S, Pelc L, Warltier D (1992) Myocardial and endothelial dysfunction after multiple brief coronary occlusions: role of oxygen radicals. Am J Physiol 236: H1703-H1709

10. Headrick J, Angello D, Berne R (1990) Effects of brief coronary occlusion and reperfusion on porcine coronary artery reactivity. Circulation 82: 2163-2169

11. McFalls E, Duncker D, Krams R, Ward H, Gornick C, Verdouw P (1991) Endothelium dependent vasodilatation following brief ischaemia and reperfusion in anaesthetised swine. Cardiovascular Research 25: 659-665

12. Kirkeboen $K$, Aksnes $G_{1}$ Ilebekk A (1990) Coronary reactivity in the porcine heart after short lasting myocardial ischaemia: effects of duration of ischaemia and myocardial stunning. Cardiovascular Research 24: 998-1007
13. Ehring $T$, Krajcar $M$, Baumgart D, Kornpa S, Hummelgen M, Heusch G (1995) Cholinergic and alpha-adrenergic coronary constriction with increasing ischemia-reperfusion injury. Am J Physiol 268: H886-H894

14. Henry T, Archer S, Nelson D, Weir E, From A (1993) Postischemic oxygen radical production varies with duration of ischemia. Am J Physiol 33: H1478$\mathrm{H} 1484$

15. Tsao P, Aoki N, Lefer D, Johnson III G, Lefer A (1990) Time course of endothelial dysfunction and myocardial injury duxing myocardial ischemia and reperfusion in the cat. Circulation 82: 1402-1412

16. Hartley C, Cole J (1974) An ultrasonic pulsed Doppler system for measuring blood flow in small vessels. I Appl Physiol 37: 626

17. Bristow J, McFalls E, Anselone C, Pantely G (1987) Coronary vasodilator reserve persists despite tachycardia and myocardial ischemia. Am J Physiol 253: $\mathrm{H} 422-\mathrm{H} 431$

18. Duncker D, McFalls E, Krams R, Verdouw P (1992) Pressure-maximal coronary flow relationship in regionaily stunned porcine myocardium. Am J Physiol 262: H1744-H1751 
19. McFalls E, Duncker D, Sassen L, Gho B, Verdouw P (1991) Effect of antiischemic therapy on coronary flow reserve and the pressure-maximal coronary flow relationship in anesthetized swine. Journal of Cardiovascular Pharmacology 18: 827-836

20. Johnson W, Malone S, Pantely G, Anselone C, Bristow J (1988) No reflow and extent of infarction during maximal vasodilation in the porcine heart. Circulation 78: 462-472

21. Bolli R, Triana J, Jeroudi M (1990) Prolonged impairment of coronary vasodilation after reversible ischemia. Circ Res 67: 332-334

22. Nicklas J, Gips J (1989) Decreased coronary flow reserve after transient myocardial ischemia in dogs. J Am Coll Cardiol 13: 195-199

23. Jeremy R, Stahl L, Gillinov M, Litt M, Aversano T, Becker L (1989) Preservation of coronary flow reserve in stunned myocardium. Am J Physiol 256: H1303H1310

24. Vanhaecke J, Flameng W, Borgers M, Jang I, Van de Werf F, de Geest H (1990) Evidence for decreased coronary flow reserve in viable postischemic myocardium. Circ Res 67: 1201-1210
25. Laxson D, Homans D, Dai X, Sublett E, Bache R (1989) Oxygen consumption and coronary reactivity in postischemic myocardium. Circ Res 64: 9-20

26. Klocke $F$ (1987) Measurements of coronary flow reserve: defining pathophysiology versus making decisions about patient care. Circulation 76: 1183-1189

27. Pelc L, Garancis J, Gross G, Warltier D (1990) Alteration of endotheliumdependent distribution of myocardial blood flow after coronary occlusion and reperfusion. Circulation 81: 1928-1937

28. Dauber I, Lesnefsky E, VanBenthuysen K, Weil J, Horwitz L (1991) Reactive oxygen metabolite scavengers decrease functional coronary microvascular injury due to ischemia-reperfusion. Am J Physiol 260: H42-H49

29. Bache R, Cobb F (1977) Effect of maximal coronary vasodilation on transmural myocardial perfusion during tachycardia in the awaka dog. Circ Res 41: 648-653

30. Aversano T, Klocke F, Mates R, Canty Jr J (1984) Preloadinduced alterations in capacitance-free diastolic pressure-flow relationships. Am J Physiol 246: H410 $\mathrm{H} 417$

31. Krams R, Sipkema P, Zegers J, Westerhof N (1989) Contractility is the main determinant of coronary systolic flow impediment. Am J Physiol 257: H1936H1944
32. Marzilli M, Goldstein S, Sabbah $\mathrm{H}$, Lee T, Stein P (1979) Modulating effect of regional myocardial performance on local myocardial perfusion in the dog. Circ Res 45: 634641

33. Dauber I, VanBenthuysen K, McMurtry I, Wheeler G, Lesnefsky E, Horwitz L, Weil J (1990) Functional coronary microvascular injury evident as increased permeability due to brief ischemia and reperfusion. Circulation 66: 986-998

34. Pantely G, Ladley H, Bristow J (1984) Low zero-flow pressure and minimal capacitance effect on diastolic coronary arterial pressure-flow relationships during maximum vasodilation in swine. $\mathrm{Cir}-$ culation 70: 485-494

35. Kaley G, Rodenburg J, Messina E, Wolin M (1989) Endothelium-associated vasodilators in rat skeletal muscle microcirculation. Am J Physiol 256: H720$\mathrm{H} 725$

36. Houston D, Shepherd J, Vanhoutte P (1985) Adenine nucleotides, serotonin, and endothelium-dependent relaxations to platelets. Am J Physiol 248: H389H395 